\title{
Comparative Study of Hyperbaric Bupivacaine Plus Ketamine Vs Bupivacaine Plus Fentanyl for Spinal Anaesthesia during Caeserean Section
}

\section{Shrestha SK, Bhattarai B, Shah R}

\author{
Department of Anesthesia \\ Dhulikhel Hospital - Kathmandu University Hospital \\ Kathmandu University School of Medical Sciences \\ Dhulikhel, kavre, Nepal \\ Corresponding author \\ Santosh Kumar Shrestha \\ Department of Anesthesia \\ Dhulikhel Hospital - Kathmandu University Hospital \\ Kathmandu University School of Medical Sciences \\ Dhulikhel, kavre, Nepal \\ E-mail: drsantosh_shrestha@yahoo.com
}

\section{Citation}

Shrestha SK, Bhattarai B, Shah R. Comparative Study of Hyperbaric Bupivacaine Plus Ketamine Vs Bupivacaine Plus Fentanyl for Spinal Anaesthesia During Caeserean Section. Kathmandu Univ Med J 2013;44(4):287-291.

\begin{abstract}
Background

Spinal anesthesia is widely used for caesarean section due to its rapid onset, low failure rate, complete analgesia. Addition of intrathecal ketamine and opioids to local anaesthetics seems to improve the quality of block and prolong the duration of analgesia.
\end{abstract}

\section{Objectives}

The purpose of this study was to compare the effect of intrathecal ketamine mixed with hyperbaric bupivacaine to intrathecal fentanyl mixed with hyperbaric bupivacaine.

\section{Methods}

One hundred parturients ASA Grade I scheduled for elective or semiurgent caesarean section under spinal anaesthesia were randomly divided into two groups. Group A received $2 \mathrm{ml}(10 \mathrm{mg}$ ) hyperbaric bupivacaine $0.5 \%$ plus $25 \mathrm{mg}$ preservative free ketamine. Group B received $2 \mathrm{ml}(10 \mathrm{mg})$ hyperbaric bupivacaine $0.5 \%$ plus $25 \mu \mathrm{g}$ fentanyl. The patients were observed intraoperatively for the onset of sensory block, degree of motor block and total duration of analgesia.

\section{Results}

The time to achieve Bromage scale 3 motor blockade was shorter in Group A than in Group B. $(p=0.445)$ whereas time to achieve highest dermatomal level of sensory block was shorter in Group A than in Group B $(p=0.143)$. The duration of spinal analgesia was longer in Group $B$ than in Group $A(p=0.730)$. The frequency of side effect such as sedation score was higher in Group A compared to Group B ( $p=$ 0.048 ). The incidence of pruritus was significantly higher in Group B compared to Group A $(p=0.000)$.

\section{Conclusion}

Addition of preservative free ketamine lead to faster onset of sensory and motor blockade, although it did not prolong the duration of spinal analgesia compared to addition of fentanyl in parturients undergoing caesarean section with spinal anaesthesia.

\section{KEY WORDS}

Bupivacaine, caesarean section, fentanyl, ketamine, spinal anaesthesia 


\section{INTRODUCTION}

Neuraxial blockade for caeserean section has become increasingly popular as it produces rapid onset of analgesia and complete muscle relaxation. Risk of aspiration, drug induced neonatal depression and many more problems associated with general anaesthesia may largely be avoided by using neuraxial techniques.

Hyperbaric bupivacaine $0.5 \%$ is commonly used for spinal anaesthesia. However, sometimes bupivacaine may fail to prevent visceralgia and the induced pain during traction of peritonium. ${ }^{1}$ Intrathecal adjuncts, such as ketamine, opioids, vasoconstrictors, alpha 2 agonists, and neostigmine are often added to enhance spinal anaesthesia. ${ }^{2-6}$

Ketamine is a potent anaesthetic agent with analgesic properties and has been found to be effective by epidural and intrathecal routes. Its mode of action includes non competitive antagonism at $\mathrm{N}$ methyl $\mathrm{D}$ aspartate (NMDA) receptors and a local anaesthetic effects. ${ }^{7}$ It possessess some definite advantage over conventional local anaesthetic agents as it stimulates cardiovascular system and respiratory system..$^{8,9}$

Fentanyl, a lipophilic opioid, has rapid onset of action following intrathecal administration. The clinical efficacy of intrathecal opioids to relieve visceral pain has been well demonstrated. ${ }^{10,11}$ Neuraxial opioids allows prolonged analgesia in the postoperative period and faster recovery from spinal anaesthesia. ${ }^{12}$

The aim of the present study was to observe the effect of intrathecal ketamine $25 \mathrm{mg}$ added to $0.5 \%$ hyperbaric bupivacaine compared to intrathecal fentanyl $25 \mu \mathrm{g}$ added to $0.5 \%$ hyperbaric bupivacaine with regard to sensory and motor blockade, intraoperative hemodynamics, duration of analgesia, neonatal outcome.

\section{METHODS}

After obtaining approval from hospital ethical committee and informed written consent, 100 parturients of ASA I scheduled for elective or semiurgent caeserean delivery were enrolled in this prospective, randomized, double blinded study. The study was conducted at Dhulikhel hospital, kathmandu university hospital, between May 2012 and October 2012. Exclusion criteria included co existing disease such as pre eclampsia and hepato renal disease, any contraindication to regional anaesthesia, allergy to applied drugs, long term opioid use or history of chronic pain. No patients refused to participate in this randomised study. All necessary investigation were carried out.

All the patients were given Inj Ranitidine $50 \mathrm{mg}$ and Inj Metoclopromide $10 \mathrm{mg}$ half an hour before the surgery. Hundred patients were divided randomly into two groups of fifty each. Group A : received $2 \mathrm{ml}(10 \mathrm{mg})$ hyperbaric bupivacaine $0.5 \%+25 \mathrm{mg}$ ketamine $(0.5 \mathrm{ml})$ preservative free Total $2.5 \mathrm{ml}$.
Group B : received $2 \mathrm{ml}(10 \mathrm{mg})$ hyperbaric bupivacaine $0.5 \%$ $+25 \mu \mathrm{g}$ fentanyl $(0.5 \mathrm{ml})$ Total $2.5 \mathrm{ml}$.

Preloading was done with $10 \mathrm{ml} / \mathrm{kg} \mathrm{m}$ of Ringer's lactate solution. Monitoring included pulse oximetry, ECG and noninvasive blood pressure measurement cycled at 5 minute interval. Under all aseptic precautions lumbar puncture was performed with 25 gauge Quincke's needle in the L3 -L4 space in the sitting position and the study drugs were injected as per group of the patient according to random assignment by anaesthesiologist who was unaware of the study. After noting the time of injection, patient was immediately placed in supine position with left uterine displacement.

The onset of sensory block was assessed by pinprick to skin till the level stabilized for three consecutive tests and was defined as the time from spinal block to peak sensory dermatome level. Regression time to reach sensory level upto T12 was recorded. Motor block was assessed by modified Bromage score.

0 No motor block

1 Inability to flex hip

2 Inability to flex knee

3 Inability to flex ankle

The time taken to reach Bromage score 3 was calculated as onset motor blocked and time taken to reach Bromage score 0 was duration of motor blockade. Duration of analgesia was measured as the time from induction of block to first patient request for supplemental analgesia.

Hypotension was defined as either a systolic blood pressure of less than $90 \mathrm{mmHg}$ or a decrease of more than $20 \%$ of baseline and was treated with IV fluids and IV phenylephrine $50 \mu \mathrm{g}$ bolus. If HR was less than 50 beats per minute, $0.6 \mathrm{mg}$ of atropine was administered IV. Maximum sedation score was also recorded using these category.

\section{Awake}

\section{Drowsy}

\section{Asleep respond normally}

3 Asleep respond to tactile stimuli

\section{Not responding}

Presence of side effect mainly nausea, vomiting, pruritus were noted. Neonatal well being was assessed by APGAR score at 1 and 5 minutes.

Sample size was calculated on the basis of previous study by Unlugenc et al who studied double blind comparison of intrathecal $\mathrm{S}(+)$ ketamine and fentanyl combined with bupivacaine $0.5 \%$ for caeserean section. ${ }^{2}$ In our part of the country spinal anaesthesia for caeserean section are commonly performed using $0.5 \%$ bupivacaine $(\mathrm{H})$. We wanted to assess the effect of adjuvant ketamine and fentanyl added to $0.5 \%$ Bupivacaine $(\mathrm{H})$. A power analysis was performed as a component of design to estimate the required total sample size as a function of power $1-\beta=0.80$ 
and $\alpha=0.05$. Data were analysed by using independent sample ' $\mathrm{t}$ ' test and chi-square test. $\mathrm{P}$ value $<0.05$ was considered statistically significant. Data are presented as mean values \pm SD.

\section{RESULTS}

There were 50 patients in each group and there was no significant statistical differences among the two groups with respect to age, weight, duration of surgery and intraoperative fluid requirement ( Table 1).

Table 1. Demographic Profile of Two Groups with Mean S.D Values.

\begin{tabular}{|lcc|}
\hline & Group A & Group B \\
\hline Number of patients & 50 & 50 \\
\hline Age & $24.66 \pm 5.278$ & $23.96 \pm 4.286$ \\
\hline Weight $(\mathrm{kg})$ & $54.36 \pm 3.269$ & $55.28 \pm 5.031$ \\
\hline Duration of surgery & $54.46 \pm 9.803$ & $56.32 \pm 11.807$ \\
\hline Intraoperative fluid requirement & $1490 \pm 342.410$ & $1590 \pm 314.448$ \\
\hline
\end{tabular}

There was no statistically significant differences in heart rate among the two groups except at 60 and 90 minutes where it was statistically significant( Table 2).

Table 2. Changes in Heart Rate.

\begin{tabular}{|cccc|}
\hline Time & $\begin{array}{c}\text { Group A } \\
\text { (Mean } \pm \text { SD) }\end{array}$ & $\begin{array}{c}\text { Group B } \\
\text { (Mean } \pm \text { SD) }\end{array}$ & P value \\
\hline Preop & $91.16 \pm 15.030$ & $94.92 \pm 15.767$ & 0.795 \\
\hline 5 & $84.56 \pm 17.463$ & $89.54 \pm 17.403$ & 0.823 \\
\hline 10 & $81.80 \pm 16.438$ & $86.80 \pm 16.589$ & 0.755 \\
\hline 15 & $80.58 \pm 16.650$ & $83.58 \pm 14.445$ & 0.639 \\
\hline 20 & $81.38 \pm 17.391$ & $88 \pm 17.284$ & 0.803 \\
\hline 25 & $83.26 \pm 15.275$ & $84.78 \pm 15.643$ & 0.650 \\
\hline 30 & $81.36 \pm 14.575$ & $87.28 \pm 14.813$ & 0.497 \\
\hline 40 & $80.14 \pm 13.473$ & $87.08 \pm 16.379$ & 0.091 \\
\hline 50 & $78.34 \pm 13.215$ & $82.48 \pm 15.496$ & 0.339 \\
\hline 60 & $78.68 \pm 11.736$ & $82.60 \pm 15.426$ & 0.050 \\
\hline 90 & $76.92 \pm 9.706$ & $81.50 \pm 13.443$ & 0.018 \\
\hline
\end{tabular}

There was statistically significant difference in Systolic blood pressure among the two groups at 15 minutes. The changes in systolic blood pressure at other interval of time was comparable(Table 3).

The changes in diastolic blood pressure between the two groups was not statistically significant( Table 4).

The characteristics of sensory block in the two groups are listed in table 5 . The median highest level of sensory block in both groups was T5. There was no statistically significant difference among the two groups in time to achieve highest sensory block and regression of sensory block to reach $T$ 12.

Table 6 shows that there was no statistically significant difference in achieving Bromage 3 motor blockade between the two groups. The time for regression to Bromage scale
Table 3. Changes in Systolic Blood Pressure.

\begin{tabular}{|cccc|}
\hline Time & $\begin{array}{c}\text { Group A } \\
\text { (Mean } \pm \text { SD) }\end{array}$ & $\begin{array}{c}\text { Group B } \\
\text { (Mean } \pm \text { SD) }\end{array}$ & P value \\
\hline Preop & $126.76 \pm 12.208$ & $123.62 \pm 13.619$ & 0.586 \\
\hline 5 & $106.14 \pm 15.417$ & $106.18 \pm 14.502$ & 0.606 \\
\hline 10 & $105.98 \pm 15.264$ & $100.56 \pm 14.045$ & 0.988 \\
\hline 15 & $103.62 \pm 10.150$ & $102.22 \pm 13.488$ & 0.019 \\
\hline 20 & $101.96 \pm 13.656$ & $101.10 \pm 13.421$ & 0.682 \\
\hline 25 & $101.20 \pm 10.808$ & $102.34 \pm 12.981$ & 0.349 \\
\hline 30 & $101.66 \pm 11.464$ & $105.80 \pm 13.387$ & 0.342 \\
\hline 40 & $104.32 \pm 13.690$ & $107.04 \pm 13.132$ & 0.699 \\
\hline 50 & $108.76 \pm 14.375$ & $108.74 \pm 15.172$ & 0.951 \\
\hline 60 & $110.14 \pm 14.310$ & $111.66 \pm 16.043$ & 0.978 \\
\hline 90 & $113.42 \pm 12.581$ & $113.18 \pm 12.037$ & 0.423 \\
\hline
\end{tabular}

Table 4. Changes in Diastolic Blood Pressure.

\begin{tabular}{|cccc|}
\hline Time & $\begin{array}{c}\text { Group A } \\
\text { (Mean } \pm \text { SD) }\end{array}$ & $\begin{array}{c}\text { Group B } \\
\text { (Mean } \pm \text { SD) }\end{array}$ & P value \\
\hline Preop & $126.76 \pm 12.208$ & $123.62 \pm 13.619$ & 0.586 \\
\hline 5 & $106.14 \pm 15.417$ & $106.18 \pm 14.502$ & 0.606 \\
\hline 10 & $105.98 \pm 15.264$ & $100.56 \pm 14.045$ & 0.988 \\
\hline 15 & $103.62 \pm 10.150$ & $102.22 \pm 13.488$ & 0.019 \\
\hline 20 & $101.96 \pm 13.656$ & $101.10 \pm 13.421$ & 0.682 \\
\hline 25 & $101.20 \pm 10.808$ & $102.34 \pm 12.981$ & 0.349 \\
\hline 30 & $101.66 \pm 11.464$ & $105.80 \pm 13.387$ & 0.342 \\
\hline 40 & $104.32 \pm 13.690$ & $107.04 \pm 13.132$ & 0.699 \\
\hline 50 & $108.76 \pm 14.375$ & $108.74 \pm 15.172$ & 0.951 \\
\hline 90 & $110.14 \pm 14.310$ & $111.66 \pm 16.043$ & 0.978 \\
\hline
\end{tabular}

Table 5. Sensory Blockade.

\begin{tabular}{|c|c|c|c|}
\hline & Group A & Group B & $\begin{array}{c}P \\
\text { value }\end{array}$ \\
\hline $\begin{array}{l}\text { Highest level of } \\
\text { block(Median) }\end{array}$ & T5 & T5 & \\
\hline $\begin{array}{l}\text { Time to achieve highest } \\
\text { sensory block(min) }\end{array}$ & $6.50 \pm 1.418$ & $8.32 \pm 1.974$ & 0.143 \\
\hline $\begin{array}{l}\text { Duration of sensory } \\
\text { level to reach T12(min) }\end{array}$ & $118.20 \pm 12.202$ & $131.18 \pm 14.705$ & 0.238 \\
\hline
\end{tabular}

Table 6. Motor Blockade.

\begin{tabular}{|llll|} 
& Group A & Group B & P Value \\
\hline $\begin{array}{l}\text { Time to achieve } \\
\text { Bromage scale 3 }\end{array}$ & $3.66 \pm 0.848$ & $4.86 \pm 1.050$ & 0.445 \\
$\begin{array}{l}\text { Time to achieve } \\
\text { Bromage scale 0 }\end{array}$ & $99.48 \pm 10.324$ & $110.32 \pm 16.765$ & 0.000 \\
\hline
\end{tabular}

0 in group A was $99.48 \pm 10.324$ and that in Group B was $110.32 \pm 16.765$ which was statistically significant.

Table 7 shows that the duration of analgesia was prolonged in Group B compared to Group A but was not statistically significant.

Table 8 shows that patients in Group A were more sedated than in Group B but the values were not statistically significant. Nausea and vomiting was noted in 2 patients 
Table 7. Duration of Analgesia.

\begin{tabular}{|llll|} 
& Group A & Group B & P value \\
\hline $\begin{array}{l}\text { Duration of } \\
\text { analgesia }\end{array}$ & $137.34 \pm 14.821$ & $152.06 \pm 15.015$ & 0.730 \\
\hline
\end{tabular}

Table 8. Complication.

\begin{tabular}{|llll|}
\hline & Group A & Group B & P Value \\
\hline Sedation & 23 & 14 & 0.048 \\
\hline Nausea / Vomiting & 2 & 2 & 0.691 \\
\hline Pruritus & 0 & 14 & 0.000 \\
\hline
\end{tabular}

each in Group A and Group B. Pruritus was observed in 14 patients in Group B but none patients in Group A developed pruritus.

The mean APGAR score between the two groups at 1 minutes were $7.18 \pm 0.825$ and $7.16 \pm 0.866$ respectively which was not statistically significant( Tab 9). The better neonatal APGAR score was obtained in Group A compared to Group B at 5 minutes interval and it was statistically significant.

\section{DISCUSSION}

The principle finding in this study was that addition of preservative free ketamine $25 \mathrm{mg}$ to $10 \mathrm{mg}$ of hyperbaric bupivacaine led to faster onset of both sensory and motor blockade, although it didnot prolong the duration of spinal analgesia compared to addition of fentanyl $25 \mu \mathrm{g}$ to $10 \mathrm{mg}$ of hyperbaric bupivacaine undergoing caesarean section with spinal anaesthesia.

Different conflicting results are published in the literature, regarding the analgesic benefits of intrathecal ketamine combined with bupivacaine. Togal and colleagues demonstrated that addition of intrathecal ketamine to spinal bupivacaine had shorter sensory and motor block onset time, shorter duration of action and less motor blockade in patients undergoing transurethral resection of prostrate..$^{13}$ Singh et al studied preservative free ketamine $50 \mathrm{mg}$ mixed with $2-2.5 \mathrm{ml}$ of $0.5 \%$ bupivacaine and was injected intrathecally. ${ }^{14}$ They showed that the mixture produced quick sensory block. The duration of analgesia was 4-12 hours and was definitely better than bupivacaine alone.

Unlungenac et al studied the double blind comparison of intrathecal S+ ketamine and fentanyl combined with bupivacaine $0.5 \%$ for caesarean delivery. ${ }^{2}$ They showed that addition of $\mathrm{S}+$ ketamine $(0.05 \mathrm{mg} / \mathrm{kg})$ to $10 \mathrm{mg}$ of plain bupivacaine $(0.5 \%)$ lead to rapid onset of sensory blockade and enhanced the segmental spread of spinal blockade.

In our study we observed that addition of preservative free ketamine combined with bupivacaine lead to faster onset of sensory and motor blockade, it didnot prolong the duration of spinal analgesia compared to bupivacaine - fentanyl mixture. The reasons for improvement in spinal analgesia may be due to its potent analgesia effects produced by its action in the nucleus reticularis gigantocelluralis in the brain stem, its affinity for opioids receptor and non competitive NMDA( N methyl D aspartate) receptor antagonism. ${ }^{15}$

Kathirvel et al evaluated the effects of intrathecal ketamine added to bupivacaine for spinal analgesia. ${ }^{16}$ They showed that although addition of ketamine to spinal bupivacaine had local anaesthetic sparing effects, it didnot provide extended postoperative analgesia or decrease the postoperative analgesia requirement. More over the central adverse effects of ketamine limits its spinal injection. They also showed that the requirement of IV fluids in the perioperative periods were less in the ketamine group. Our study contradict with the study that we didnot find statistically significant difference in the requirement of intraoperative fluids between ketamine and fentanyl mixed with bupivacaine.

Govindan et al studied intrathecal ketamine in surgeries for lower abdomen and lower extremities and found that due to cardiovascular stimulant action of ketamine, there was a mild rise in heart rate and blood pressure which is a definite advantage over local anaesthetics. ${ }^{17}$ Contradictory to the study we didnot observe any rise in hemodynamic parameters with ketamine compared to fentanyl mixed with bupivacaine.

Various studies has demonstrated the prolongation of spinal analgesia by use of opioids such as fentanyl. ${ }^{12,18}$ Harsoor studied spinal anaesthesia with low dose bupivacaine with fentanyl for caesarean section and found that intrathecal fentanyl added to bupivacaine enhances quality of intraoperative analgesia, prolongs the duration of analgesia, without effecting the newborn clinical status. ${ }^{19}$ It has no action on onset of either sensory or motor block. Our study also showed that intrathecal fentanyl added to bupivacaine prolong the duration of analgesia, moreover intrathecal fentanyl bupivacaine mixture has no added advantage on the onset of sensory and motor blockade compared to ketamine bupivacaine mixture.

The spinal and supraspinal effects of ketamine and fentanyl has been demonstrated in previous studies. ${ }^{13,20-22}$ In our study, the addition of ketamine to spinal bupivacaine didnot result in lower side effects compared to spinal bupivacaine fentanyl mixture. Fourteen patients in the fentanyl bupivacaine group but none of the patients in the ketamine bupivacaine group complained of pruritus which was statistically significant. Contradictory to our study, similar study done by Unlugenc et.al showed that although the incidence of pruritus was higher in fentanyl group compared to ketamine group but was clinically insignificant. $^{2}$

Kathirvel et al observed significant more patients in the ketamine bupivacaine mixture had sedation, dizziness, nystagmus, strange feeling and postoperative nausea vomiting. ${ }^{16}$ We did observe more patient in ketamine bupivacaine group with high sedation score but was not clinically significant and we didnot observe any differences in the nausea and vomiting between the two groups.

We didnot observe any adverse effect on the neonates outcome by APGAR score between the two groups. 
The neonatal APGAR score at one minute interval was not significant but that at five minutes was statistically significant between the two groups, which is contradictory to the similar previous study by Unlugenc where the APGAR score at one and five minutes were not statistically significant between the two groups. ${ }^{2}$

This study's limitation included that blood gas analysis of umbilical blood of neonates was not carried out and neonatal well being was assessed using APGAR score only. Moreover, we didnot take into account the failed block and whether the adjuvant added might some role in the incidence of failed block.

\section{CONCLUSION}

Addition of preservative free ketamine $25 \mathrm{mg}$ to $10 \mathrm{mg}$ of hyperbaric bupivacaine $0.5 \%$ led to faster onset of both sensory and motor blockade, although it didnot prolong the duration of spinal analgesia compared to addition of fentanyl $25 \mu \mathrm{g}$ to $10 \mathrm{mg}$ of hyperbaric bupivacaine $0.5 \%$ undergoing caesarean section with spinal anaesthesia.

\section{ACKNOWLEDGEMENT}

We would like to thank Mr Roshan Mahato, Department of Community Medicine for his assistance in statistical analysis.

\section{REFERENCES}

1. Pedersen $\mathrm{H}$, Santos $\mathrm{AC}$, Steinberg ES. Incidence of visceral pain during cesarean section: the effect of varying doses of spinal anaesthesia. Anaes Analg. 1989;69:46-9.

2. Unlugenc $\mathrm{H}$, Ozalevli, Gunes Y. A double blind comparison of intrathecal $\mathrm{S}(+)$ ketamine and fentanyl combined with bupivacaine 0.5\% for caeserean section. Eur J Anaesthesiol. 2006;23:1018-1024.

3. Biswas B, Rudra A, Bose B. Intrathecal fentanyl with hyperbaric bupivacaine improves analgesia during caeserean delivery and in early postoperative period. Indian J Anaesth. 2002;46:469-472.

4. Sakura S, Sumi M, Sakaguchi Y. The addition of phenylephrine contributes to the development of transient neurologic symptoms after spinal anaesthesia with $0.5 \%$ tetracaine. Anesthesiology $1997 ; 87: 771-8$

5. Eisenach JC, De Kock M, Klimscha W. Alpha 2 adrenergic agonists for regional anaesthesia. A clinical review of clonidine 1984-95. Anaesthesiology. 1996;85:655-74.

6. Liu SS, Hodgson PS, Moore JM. Dose response effects of spinal neostigmine added to bupivacaine spinal anaesthesia in volunteers. Anesthesiology. 1999;90:710-17.

7. Hirota K,Lambert DG. Ketamine: its mechanism of action and unusual clinical uses. British journal of Anaesthesia. 1996;77:441-4.

8. Bansal SK, Bhatia VK, Bhatnagar NS. Evaluation of intrathecal ketamine in emergency surgery. Ind J Anaesth. 1994;42:32-36.

9. Soliman MG, Brinale GF, Kuster G. Response of hypercapnia under ketamine anaesthesia. Can Anaesth Soc J. 1975;22:486.

10. Hunt CO, Naulty JS, Bader AM. Perioperative analgesia with subarachnoid fentanyl bupivacaine for caeserean delivery. Anaesthesiology. 1989;71:535-40.

11. Courtney MA, Bader AM, Hartwell. Perioperative analgesia with subarachnoid sufentanil administration. Reg Anesth. 1992;17:274-8.

12. Kuusniemi KS, Pihlajamaki KK, Pitkanen MT. The use of bupivacaine and fentanyl for spinal anesthesia for urologic surgery. Anesth Analg 2000;91:1452-6.

13. Togal $T$, Demirbilek $S$, Koroglu A. Effects of $S(+)$ ketamine added to bupivacaine for spinal anaesthesia for prostrate surgery in elderly patients. Eur J Anaesthesiol. 2004;21:193-197.

14. Singh SP, Sinha AK, Jha AK. Evaluation of intrathecal ketamine for intraoperative and postoperative analgesia. Indian Journal of Anaesthesia. 1997;41(4):15-8.

15. Clements JA, Nimmo WS. Pharmacokinetics and analgesic effects of ketamine in man. Br J Anaesth. 1981;53:27-30.

16. Kathirvel S, Sadhasivam S, Saxena A. Effects of intrathecal ketamine added to bupivacaine for spinal anaesthesia. Anaesthesia 2000;55:899-910.

17. Govindan K, Krishnan R, Marc P. Intrathecal ketamine in surgeries for lower abdomen and lower extremities. Proc. West. Pharmacol. Soc 2001;44:197-199.

18. Palmer CM, Voulgaropoulos D, Alves D. Subarachnoid fentanyl augments lidocaine spinal anesthesia for caesarean delivery. Region Anesth Pain Med. 1995;20:389-394.

19. Harsoor S, Vikram M. Spinal anaesthesia with low dose bupivacaine with fentanyl for caesarean section. SAARC J Anaesth. 2008;1:142145 .

20. Bion JF. Intrathecal ketamine in war surgery. A preliminary study under field condition. Anaesthesia. 1984;39:1023-28.

21. Shende D, Cooper GM, Bowden MI. The influence of intrathecal fentanyl on the characteristic of subarachnoid block for caesarean section. Anaesthesia. 1998;79:702-710.

22. Choi DW, Ahn HJ, Kim MH. Bupivacaine sparing effect of fentanyl in spinal anaesthesia for caesarean delivery. Reg Anesth Pain Med 2000;25:240-245. 